\title{
Regulation of radiosensitivity by 4-methylumbelliferone via the suppression of interleukin-1 in fibrosarcoma cells
}

\author{
RYO SAGA $^{1}$, KAZUKI HASEGAWA ${ }^{1}$, KOSHO MURATA ${ }^{1}$, MITSURU CHIBA ${ }^{2}$, TOSHIYA NAKAMURA ${ }^{2}$, \\ KAZUHIKO OKUMURA $^{3}$, EICHI TSURUGA ${ }^{1}$ and YOICHIRO HOSOKAWA ${ }^{1}$
}

Departments of ${ }^{1}$ Radiation Sciences, and ${ }^{2}$ Bioscience and Laboratory Medicine, Graduate School of Health Sciences, Hirosaki University, Hirosaki, Aomori 036-8564; ${ }^{3}$ Department of Oral and Maxillofacial Surgery, School of Dentistry, Health Sciences University of Hokkaido, Tobetsu-cho, Ishikari-gun, Hokkaido 061-0293, Japan

Received August 1, 2018; Accepted January 17, 2019

DOI: $10.3892 / \mathrm{ol} .2019 .9990$

\begin{abstract}
Tumor recurrence and distant metastasis following radiotherapy, which can lead to poor prognosis, are caused by residual cancer cells that acquire radioresistance. Chemotherapy or a combination of targeted inhibitors can potentially enhance radiation sensitivity and prevent metastasis. It was previously reported that co-administration of the hyaluronan synthesis inhibitor 4-methylumbelliferone (4-MU) enhanced the lethality of X-ray irradiation in HT1080 human fibrosarcoma cells and decreased their invasiveness to a greater extent than either treatment alone. To clarify the molecular basis of these effects, the present study conducted mRNA expression profiling by cDNA microarray to identify the signaling pathways that are altered under this combination treatment. The activation state of the signaling pathways was classified by z-scores in the Ingenuity Pathway Analysis. The results revealed that the pro-inflammatory cytokines interleukin (IL)- 6 and IL- 8 were activated by 2 Gy X-ray irradiation, an effect that was abolished by co-administration of 4-MU. Similar trends were observed for the upstream signaling component IL-1. These results indicate that the radiosensitivity of fibrosarcoma cells is improved by suppressing inflammation through the administration of 4-MU.
\end{abstract}

\section{Introduction}

The advancement of technology has resulted in highly accurate radiation therapy for primary solid tumors (1); however, recurrence or distant metastasis due to residual cancer cells resistant to irradiation remains a major problem that leads to poor outcome (2) Radioresistance in SAS oral squamous

Correspondence to: Mr Ryo Saga, Department of Radiation Sciences, Graduate School of Health Sciences, Hirosaki University, 66-1 Hon-cho, Hirosaki, Aomori 036-8564, Japan

E-mail: sagar@hirosaki-u.ac.jp

Key words: radioresistance, inflammatory cytokine, 4-methylumbelliferone, hyaluronan cell carcinoma cells, HEp-2 laryngeal cancer cells, and lung cancer cells can be induced by fractionated radiotherapy (3-6). Combining chemotherapy (e.g. cisplatin, 5-fluorouracil, and paclitaxel) with targeted inhibitors can potentially overcome radioresistance and extend progression-free and overall survival (7-12). However, few studies have examined the efficacy of combined treatments in preventing distant metastasis (10).

4-Methylumbelliferone (4-MU) is a hyaluronan synthesis inhibitor $(13,14)$ that has demonstrated anti-tumor and -invasion/metastasis effects in various cancer cell types and mouse models of prostate and liver cancer that are exerted via suppression of hyaluronan synthase (HAS) expression $(15,16)$. 4-MU was also shown to suppress inflammatory cytokines and chemokines such as interleukin (IL)-6 and -8 (17). Elevated levels of nuclear factor $(\mathrm{NF})-\kappa \mathrm{B}$, a cytokine and transcription factor that regulates proinflammatory molecules such as IL-1 $\beta$ and IL- 6 and tumor necrosis factor (TNF) $\alpha$ induce resistance to apoptosis (18) and radiotherapy (19) in cancer cells. IL-6 is a potential therapeutic target owing to its close association with cancer stem cells $(20,21)$.

We speculated that combined administration of 4-MU which has anti-inflammatory effects and radiotherapy can not only prevent distant metastasis but also sensitize radioresistant cells to the effects of X-ray radiation. In our previous study, HT1080 human fibrosarcoma cells were exposed to 2 Gy $\mathrm{X}$-ray radiation in the presence of $100 \mu \mathrm{M} 4-\mathrm{MU}$ (22); this inhibited colony-forming ability and metastatic potential, which was accompanied by downregulation of matrix metalloproteinases-2 and -9. However, the mechanistic basis of these effects is unclear. We addressed this in the present study by performing mRNA profiling to identify factors related to the anti-tumor and -invasion effects of 4-MU in HT1080 cells.

\section{Materials and methods}

Reagents. 4-MU was purchased from Nacalai Tesque (Kyoto, Japan) and diluted in dimethylsulfoxide (Wako Pure Chemical Industries, Ltd., Osaka, Japan); the working concentration was $500 \mu \mathrm{M}$. The reason for using $500 \mu \mathrm{M} 4$-MU was that clear effects of 4-MU could be observed and the cytotoxic effect was low for normal fibroblast cells at a $500 \mu \mathrm{M}$ concentration (22). 
Monoclonal phycoerythin (PE)-conjugated anti-human cluster of differentiation (CD)126 antibody (cat. no. 352804); mouse monoclonal PE-IgG1, $\kappa$ isotype control (cat. no. 400114); monoclonal allophycocyanin (APC)-conjugated anti-human CD130 (gp130) antibody (cat. no. 362005); mouse monoclonal APC-IgG2a, $\kappa$ isotype control (cat. no. 400221); fluorescein isothiocyanate (FITC)-annexin V (cat. no. 640905); and propidium iodide (PI) (cat. no. 421301) were from BioLegend (San Diego, CA, USA). PE-conjugated polyclonal anti-human type 1 IL-1 receptor (IL-1R) antibody (cat. no. FAB269P) and PE-conjugated goat IgG (cat. no. IC108P) were R\&D Systems, Inc., (Minneapolis, MN, USA).

Cell culture. HT1080 human fibrosarcoma cells from American Type Culture Collection (Manassas, VA, USA) were cultured in Roswell Park Memorial Institute 1640 medium (Thermo Fisher Scientific, Inc., Waltham, MA, USA) supplemented with $10 \%$ heat-inactivated fetal bovine serum (FBS; Japan Bio Serum, Fukuyama, Japan) and 1\% penicillin/streptomycin (Life Technologies) at $37^{\circ} \mathrm{C}$ in a humidified atmosphere of $5 \% \mathrm{CO}_{2}$.

Clonogenic potency assay. The clonogenic potency of HT1080 cells was estimated with the colony formation assay. Appropriate numbers of cells were seeded and incubated for $2 \mathrm{~h}$, then subjected to X-ray irradiation at 1-6 Gy in the presence of $500 \mu \mathrm{M} 4-\mathrm{MU}$ followed by incubation for $24 \mathrm{~h}$. After 7-10 days of culture with regular changes of medium cells were fixed with methanol (Wako Pure Chemical Industries, Ltd.) stained by Giemsa (Wako Pure Chemical Industries, Ltd.), and quantified.

Irradiation. Ionizing radiation (IR) was delivered using an X-ray generator (MBR-1520R-3; Hitachi Medical, Co., Tokyo, Japan) with $0.5-\mathrm{mm}$ aluminum and $0.3-\mathrm{mm}$ copper filters at a distance of $45 \mathrm{~cm}$ between the focus and target $(150 \mathrm{kV}$, $20 \mathrm{~mA}, 1.0 \mathrm{~Gy} / \mathrm{min}$ ). During X-ray exposure, the total dose and dose rate were monitored with a thimble ionization chamber placed next to the sample.

Flow cytometry analysis. To evaluate the expression of the IL-6 receptors CD126 and CD130, and the IL- $1 \alpha / \beta$ receptor type I IL-1R, cells were resuspended in $100 \mu \mathrm{l}$ Dulbecco's phosphate-buffered saline without $\mathrm{CaCl}_{2}$ and $\mathrm{MgCl}$ (Takara Bio, Inc., Otsu, Japan) containing 5\% FBS and PE-conjugated anti-human CD126 antibody (3 $\mu 1 / 10^{6}$ cells), APC-conjugated anti-human CD130 antibody ( $3 \mu 1 / 10^{6}$ cells), and PE-conjugated anti-human type $1 \mathrm{IL}-1 \mathrm{R}$ antibody for $15 \mathrm{~min}$ at $4^{\circ} \mathrm{C}$ in the dark. To detect cell death, cells labeled with FITC-annexin V ( $3 \mu 1 / 10^{6}$ cells) were resuspended in annexin V binding buffer (cat. no. 422201; BioLegend) and incubated for $15 \mathrm{~min}$ at room temperature in dark with PI (6 $\mu 1 / 10^{6}$ cells), followed by flow cytometry analysis on FACS Aria instrument (BD Biosciences, Tokyo, Japan).

RNA extraction and analysis. Total RNA was extracted from HT1080 cells $24 \mathrm{~h}$ after irradiation and/or 4-MU administration using the RNeasy Mini kit (Qiagen GmbH, Hilden, Germany), and RNA quality was confirmed with an Agilent 2100 Bioanalyzer (Agilent Technologies, Inc., Santa Clara, CA, USA). Cyanine (Cy)3-labeled cRNA samples were
Table I. Primer sequences of the target genes.

\begin{tabular}{ll}
\hline Primers & \multicolumn{1}{c}{ Sequences (5'-3') } \\
\hline IL-1 $\alpha$ forward & GGTTGAGTTTAAGCCAATCCA \\
IL-1 $\alpha$ reverse & TGCTGACCTAGGCTTGATGA \\
IL-1 $\beta$ forward & TACCTGTCCTGCGTGTTGAA \\
IL-1 $\beta$ reverse & TCTTTGGGTAATTTTGGGATCT \\
IL-6 forward & CACTGGGCACAGAACTTATGTTG \\
IL-6 reverse & AAAATAATTAAAATAGTGTCCTAA \\
GAPDH forward & CGCTCAT \\
GAPDH reverse & TGAGGTCAATGAAGGGGTC
\end{tabular}

IL, interleukin.

synthesized from total RNA and hybridized to $8 \times 60 \mathrm{~K}$ format SurePrint G3 Human GE v2 microarray slides (eArray Design ID $=039494$ ) according to the manufacturer's instructions (Agilent Technologies, Inc.). Cy3 fluorescence was detected with a DNA microarray scanner (G2600A SureScan) and processed using Feature Extraction software (both from Agilent Technologies, Inc.).

Reverse transcription-quantitative polymerase chain reaction $(R T-q P C R)$. cDNA was synthesized using a RT kits (Applied Biosystems; Thermo Fisher Scientific, Inc.) and used as a template for PCR in a $20-\mu 1$ reaction mixture containing $2 \mathrm{X}$ SYBR Premix Ex Taq (Takara Bio, Inc.) and $0.5 \mu \mathrm{M}$ forward and reverse primers (Table I). The reaction was carried out on a real-time PCR system (StepOne Plus; Life Technologies) under the following conditions: $30 \mathrm{sec}$ at $95^{\circ} \mathrm{C}$, followed by 40 cycles of $95^{\circ} \mathrm{C}$ for $5 \mathrm{sec}$, and $54^{\circ} \mathrm{C}$ for $30 \mathrm{sec}$. Target gene expression levels were calculated relative to that of glyceraldehyde 3-phosphate dehydrogenase mRNA (internal control) with the comparative $\Delta \Delta \mathrm{Cq}$ method (23).

Enzyme-linked immunosorbent assay (ELISA). The levels of IL-1 $\alpha,-1 \beta$, and -6 secreted by cells were measured using the Human IL-1 $\alpha$, IL-1 $\beta$, and IL-6 DuoSet ELISA kits (all from R\&D Systems), respectively, according to the manufacturer's protocols. Cells were treated with $500 \mu \mathrm{M} 4-\mathrm{MU}$ and irradiated with 2 Gy $\mathrm{X}$ ray, followed by incubation in serum-free medium. Culture medium conditioned for $24 \mathrm{~h}$ was used for the ELISA assay. Cytokine concentration was determined per million cells.

Statistical analysis. Statistical analysis of microarray data was performed using GeneSpring (Agilent Technologies, Inc.). Upand downregulated mRNAs transcripts were selected based on fold change ( $>2$-fold) of irradiated and/or 4-MU-administered samples relative to control samples. Ingenuity Pathway Analysis (IPA; Qiagen Silicon Valley, Redwood City, CA, USA) was used for functional analysis of each transcript. The significance of differences between control and experimental cultures was evaluated with one-way analysis of variance and the Tukey-Kramer test. Statistical analyses were performed using Microsoft Excel 2010 (Microsoft Corporation, Redmond, WA, USA) with the 
A

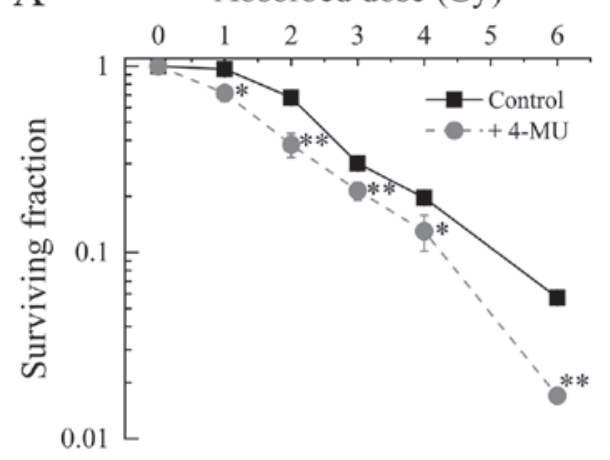

$\mathrm{C}$

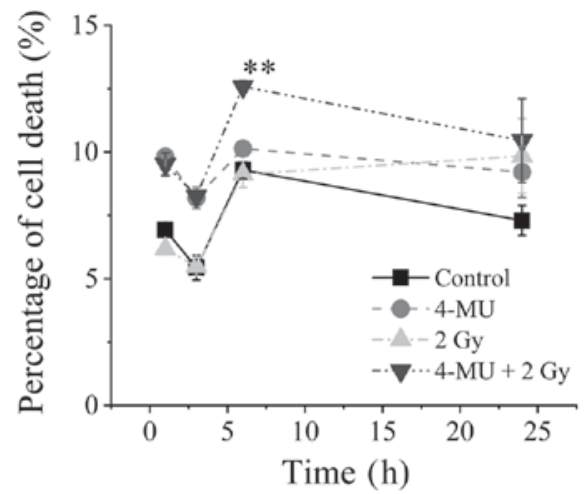

B
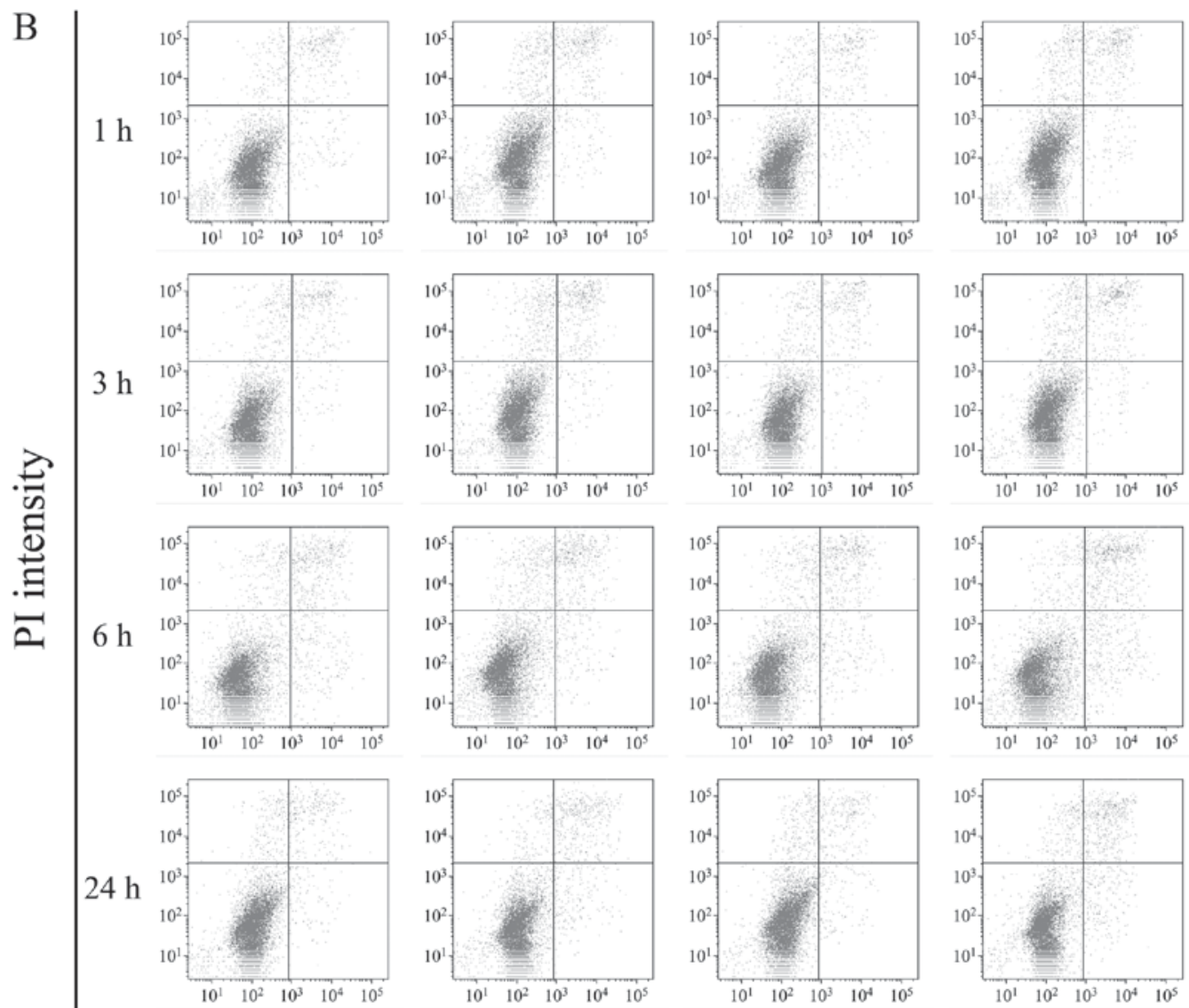

Control

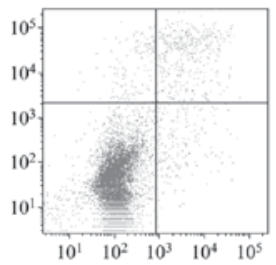

4-MU

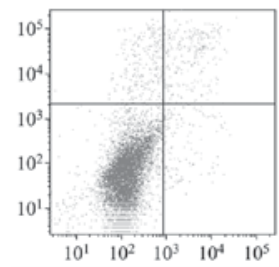

2 Gy

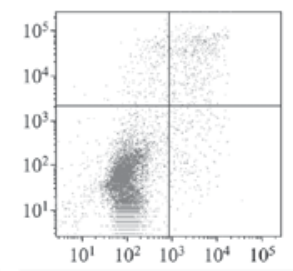

$4-\mathrm{MU}+2 \mathrm{~Gy}$

\section{FITC-Annexin V intensity}

Figure 1. Radiosensitization by 4-MU. (A) Clonogenic potency of HT1080 cells, (B) representative dot plots of FITC-Annexin V and PI staining, and (C) quantitative analysis of apoptotic cell fractions. Values are presented as the mean \pm standard deviation. ${ }^{*} \mathrm{P}<0.05$ and ${ }^{* *} \mathrm{P}<0.01$ vs. control. 4-MU, 4-methylumbelliferone; FITC, fluorescein isothiocyanate; PI, propidium iodide.

add-on software Statcel v3 (OMS Publishing, Saitama, Japan). $\mathrm{P}<0.05$ was considered to indicate a statistically significant difference.

\section{Results}

Radiosensitization by 4-MU. To investigate whether the anti-inflammatory effect of 4-MU enhances radiosensitization, we evaluated the clonogenic potency of HT1080 cells exposed to 4-MU and/or X-ray radiation with the colony formation assay. The survival of cells treated with 4-MU combined with $\mathrm{X}$-ray irradiation was decreased in a radiation dose-dependent manner compared to X-ray irradiation alone (Fig. 1A). This was confirmed by annexin V and PI staining. Representative dot plots and quantified data are shown in Fig. 1B and C. The number of cells positive for both annexin $\mathrm{V}$ and PI was increased $6 \mathrm{~h}$ after X-ray irradiation $(9.12 \pm 0.52 \%)$ (Fig. 1C). A comparable increase was observed upon treatment with 4-MU alone for $6 \mathrm{~h}(10.13 \pm 0.03 \%)$. On the other hand, there were more annexin $\mathrm{V}$ and PI positive cells in the group exposed to 
A

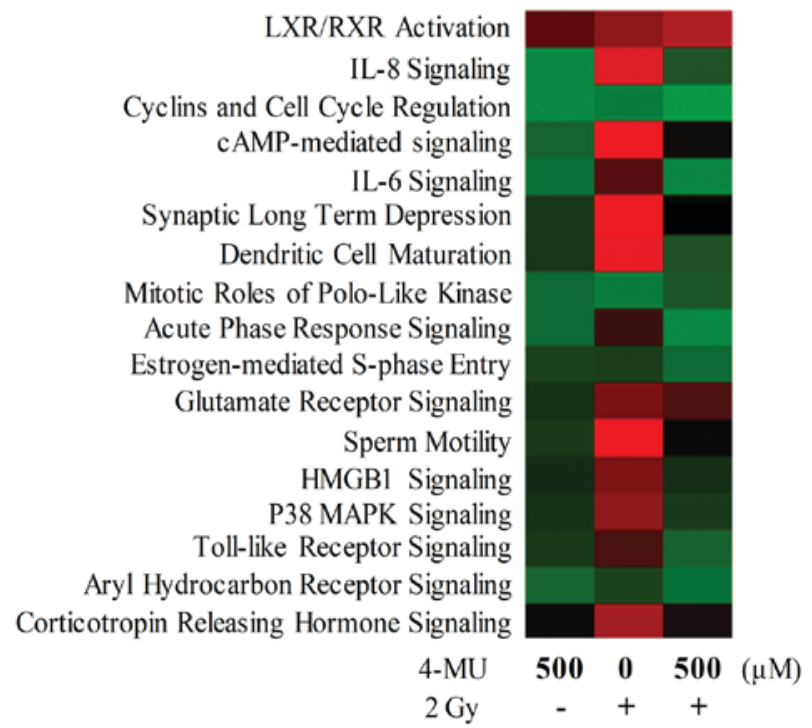

B
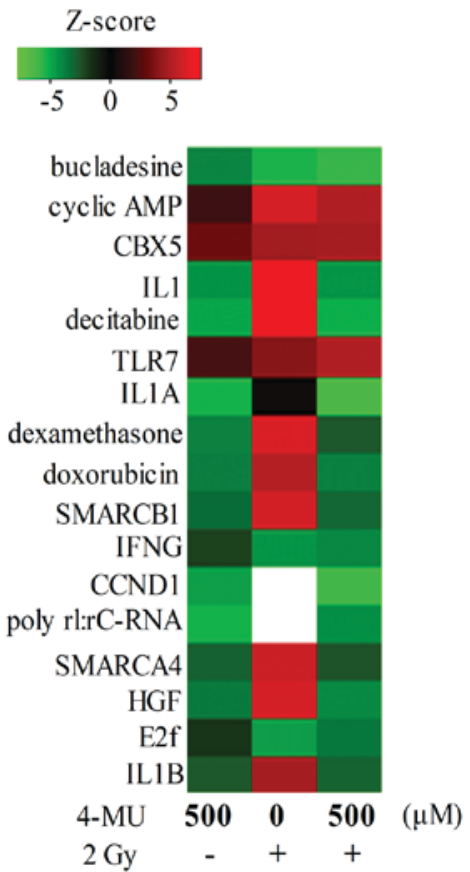

Figure 2. Analysis of signal transduction pathways and upstream genes, altered by X-ray irradiation with or without 4-MU treatment. HT1080 cells treated with $500 \mu \mathrm{M}$ 4-MU and/or $2 \mathrm{~Gy}$ X-ray irradiation were cultured for $24 \mathrm{~h}$. (A) Heatmaps of canonical pathways and (B) upstream genes were generated from z-scores calculated with Ingenuity Pathway Analysis software based on the results of global gene expression profiling. Red, green and white squares represent $\mathrm{z}$-score values of ' $2>$ ' and ' $2<$ ' and 'no data', respectively. 4-MU, 4-methylumbelliferone.

both 4-MU and X-ray radiation as compared to either treatment alone $(12.58 \pm 0.23 \%)$. These results suggest that $4-\mathrm{MU}$ enhances the sensitivity of HT1080 cells to the lethal effects of $\mathrm{X}$-ray radiation.

$m R N A$ profiling and IPA. We performed a microarray analysis to determine the signaling pathways affected by 4-MU treatment combined with X-ray irradiation. A total of 2873, 4085, and 3179 genes were differentially expressed in cells treated with 4-MU alone, X-ray alone, and 4-MU + X-ray, respectively. The IPA $\mathrm{Z}$-scores revealed that signaling pathways associated with inflammation including IL- 8 and -6 and Toll-like receptor signaling were altered by treatment with 4-MU or/and 2 Gy X-ray radiation (Fig. 2A). Moreover, IL-1 $\alpha$ and $-1 \beta$ were inactivated in cells treated with 4-MU only (Fig. 2B).

IL-1 $\alpha$, IL-1 $\beta$, and IL- 6 mRNA levels in cells and IL- $1 \alpha$, IL-1 $\beta$, and IL- 6 concentrations in the cell culture supernatant were analyzed by RT-qPCR and ELISA, respectively. IL-1 $\alpha$ and $-1 \beta$ transcript levels in cells exposed to $\mathrm{X}$-ray radiation alone were increased about 2-fold relative to the control, whereas the levels in cells treated with 4-MU showed the opposite trend (Fig. 3A). However, IL-1 $\alpha$ concentration in the supernatant was 3-fold higher in 4-MU treated as compared to control cultures $(1.73 \pm 0.21$ vs. $5.09 \pm 0.48 \mathrm{pg} / \mathrm{ml})$, whereas IL- $1 \alpha$ concentration (per $10^{6}$ cells) in the culture supernatant of cells exposed to both 4-MU and X-ray radiation was higher than that in the radiation-only group $(5.71 \pm 1.73$ vs. $2.20 \pm 0.31)$ (Fig. 3B). On the other hand, the IL-1 $\beta$ concentration in the culture supernatant was correlated with the mRNA expression. X-ray irradiation increased IL-6 mRNA level 1.7-fold relative to the control (Fig. 3A); however, the level was decreased 0.8 -fold by treatment with 4-MU combined with X-ray irradiation. IL-6 level in the culture supernatant of cells exposed to
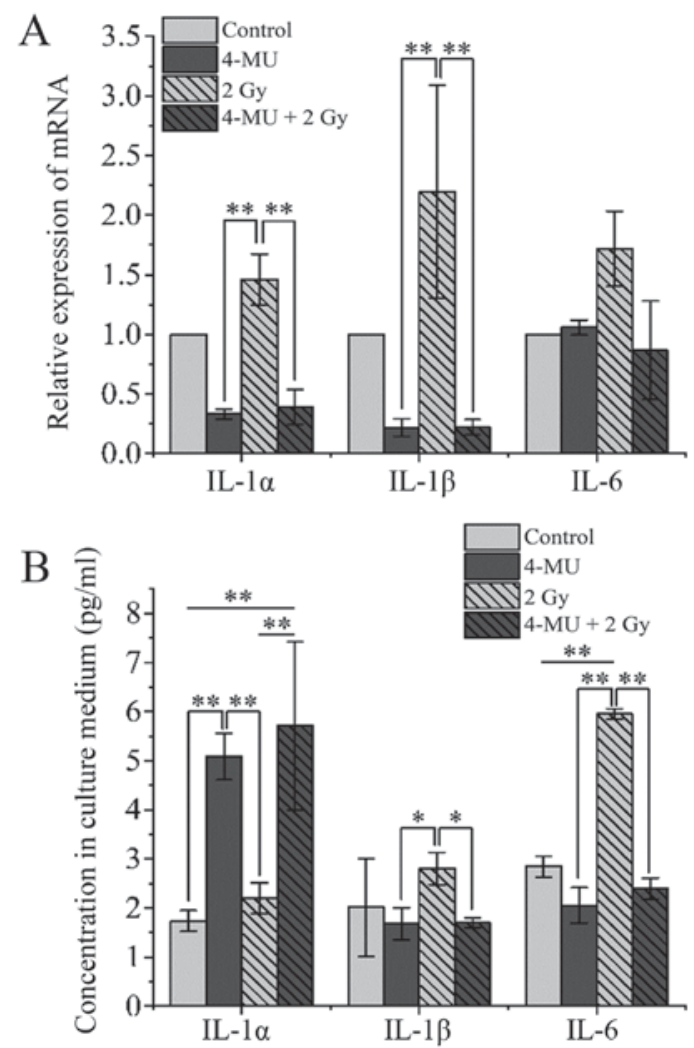

Figure 3. Validation of microarray results. (A) HT1080 cells treated with $500 \mu \mathrm{M} 4-\mathrm{MU}$ and/or $2 \mathrm{~Gy} \mathrm{X}$-ray irradiation were cultured for $24 \mathrm{~h}$. mRNA levels of IL- $1 \alpha,-1 \beta$, and -6 were evaluated by reverse transcription-quantitative polymerase chain reaction. (B) Supernatants of HT1080 cells cultured in the absence of serum with $500 \mu \mathrm{M} 4-\mathrm{MU}$ and/or 2 Gy X-ray irradiation for $24 \mathrm{~h}$ were collected and assayed by ELISA to determine IL-1 $\alpha,-1 \beta$ and -6 concentrations. Values represent the mean \pm standard deviation of the mean. ${ }^{*} \mathrm{P}<0.05$ and ${ }^{* *} \mathrm{P}<0.01$, as indicated. 4-MU, 4-methylumbelliferone; IL, interleukin. 

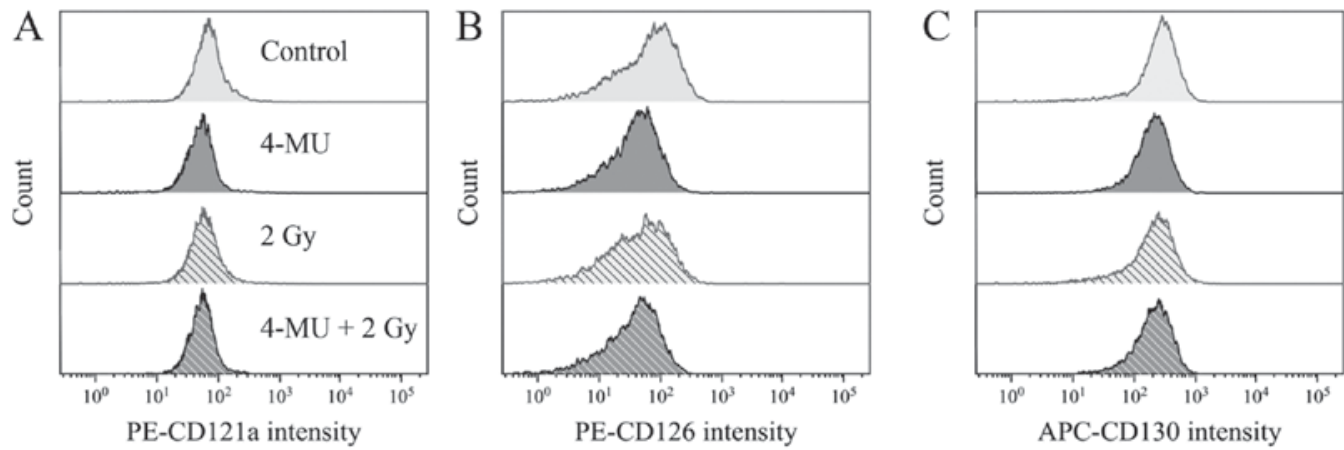

$\mathrm{D}$

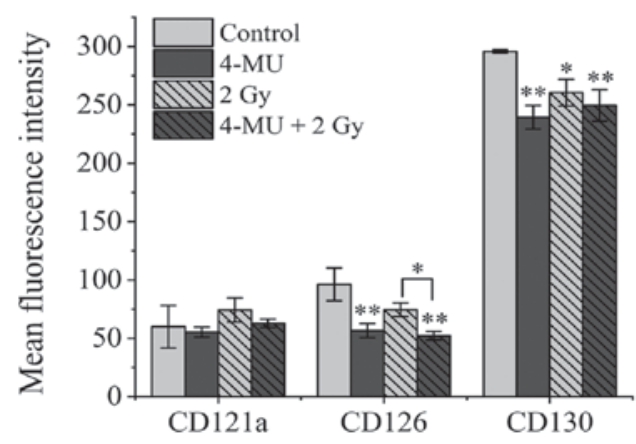

Figure 4. Flow cytometry analysis of inflammatory cytokine receptor expression. HT1080 cells treated with $500 \mu \mathrm{M} 4$-MU and/or 2 Gy X-ray irradiation were cultured for $24 \mathrm{~h}$. Cells were labeled with fluorophore-conjugated antibodies and analyzed by flow cytometry. Histograms of (A) PE-CD121a, (B) PE-CD126 and (C) APC-CD130, and (D) the quantitative analysis of mean fluorescence intensity. Values represent the mean \pm standard deviation of the mean. ${ }^{*} \mathrm{P}<0.05$ and ${ }^{* *} \mathrm{P}<0.01$ vs. control/as indicated. 4-MU, 4-methylumbelliferone; PE, phycoerythrin; CD, cluster of differentiation; APC, allophycocyanin.

radiation alone was 2 -fold higher than that in the control group $(2.84 \pm 0.21$ vs. $5.95 \pm 0.11 \mathrm{pg} / \mathrm{ml})$ (Fig. 3B), whereas concentrations for cells treated with $4-\mathrm{MU}$ with or without X-ray irradiation were similar to that of control cultures $(2.05 \pm 0.36$ and $2.39 \pm 0.21 \mathrm{pg} / \mathrm{ml}$, respectively). This suggests that the increase in IL-6 expression and release induced by X-ray irradiation was reversed by 4-MU treatment which suppressed inflammation by inhibiting IL-1 $\beta$ production.

Expression of inflammatory cytokine receptors. To investigate whether IL-1 $\alpha,-1 \beta$, and -6 receptors are suppressed by 4-MU, we examined the expression of the cognate surface receptors [type 1 IL-1R (CD121a), CD126, and CD130, respectively] by flow cytometry. The mean fluorescence intensity of CD121a on cells exposed to X-ray radiation alone was higher than that of control cells (59.88 \pm 18.3 vs. $74.29 \pm 10.3$, respectively) (Fig. 4A and D). On the other hand, the mean fluorescence intensity of CD121a in the 4-MU only (55.22 \pm 4.38$)$ and 4-MU/X-ray radiation combination $(62.79 \pm 3.72)$ groups did not differ significantly from that of the control group ( $\mathrm{P}=0.429,0.268$, respectively), suggesting that the increase in CD121a expression induced by X-ray irradiation was marginally suppressed.

The mean fluorescence intensity of CD126, the ligand binding protein for IL-6, was unaltered by X-ray irradiation relative to the control $(74.48 \pm 5.74$ vs. $96.17 \pm 14.1)$. $4-\mathrm{MU}$ treatment reduced the signal intensity to about half that of the control group (4-MU alone: $56.54 \pm 6.12$; 4-MU combined with X-ray: 52.11 \pm 3.71 ) (Fig. 4B and D). On the other hand, the mean fluorescence intensity of CD130, the signal transducer for IL- 6 receptor, was downregulated by 2 Gy X-ray irradiation as compared to the control $(260.40 \pm 11.4$ vs. $295.76 \pm 1.46)$ and was further decreased by 4-MU administration (4-MU alone:

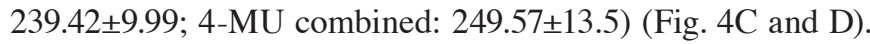
These results indicate that expression of IL-6 receptors were suppressed by 4-MU treatment.

\section{Discussion}

Recent some studies have described the anti-tumor and -invasion effects of 4-MU and the role of HAS in various malignancies (24-26). HA is closely related to cancer cell proliferation, invasion, and metastasis (27). 4-MU was reported to inhibit activation of Akt signaling by modulating the interaction between HA, CD44, and the receptor for hyaluronan-mediated motility complex (15). On the other hand, angiogenesis was suppressed by downregulation the proinflammatory cytokines IL-6 and -8 and the chemokine $\mathrm{C}-\mathrm{X}-\mathrm{C}$ motif chemokine ligand 12 (17). In accordance with these findings, we found that the increase in IL-1 $\beta$ and -6 expression caused by X-ray irradiation was abolished by 4-MU treatment. However, whether this effect leads to radiosensitization effects, needs to be verified using neutralizing antibodies and gene knockdown experiments. IL- $1 \alpha$ has been reported to consolidate cellular scaffolds in HT1080 cells (28). Liberation of cells by processes such as epithelial-mesenchymal transition is known to be the initiation of invasion into the blood vessel (29). Therefore, it was suggested that 4-MU prevents liberation of cells by promoting the release of IL-1 $\alpha$. However, conflicting IL-1 $\alpha$ between mRNA and protein levels indicate that 4-MU might have the effect of stabilizing IL- $1 \alpha$. Since 4-MU has multiple functions, further verification is necessary. 
Inflammatory cytokines have been linked to radioresistance in cancer stem cells. In particular, IL-6, an activator of the Janus kinase/signal transducer and activator of transcription 3 (STAT)3 signaling pathway, has been shown to inhibit the oxidative stress response (30) and DNA repair in non-small cell lung cancer cells $(31,32)$ and promote cancer cell resistance to radio- and chemotherapy. On the other hand, IL-1 $\beta$ promotes angiogenesis and migration and is implicated in the tumorigenicity of fibrosarcoma cells (28). Blockade of IL-1 signaling overcame erlotinib resistance in head and neck squamous cell carcinoma (33). Activation of NF- $\kappa \mathrm{B}$, plays an important role in the release of IL- $1 \beta$ and -6 and TNF $\alpha$, which triggers a positive feedback loop in the inflammatory response (34). NF- $\kappa B$ activation induces anti-apoptotic genes such as B cell lymphoma (Bcl)-2 and Bcl-extra-large leading to radio- and chemotherapeutic resistance (35). Thus, controlling the inflammatory cascade can potentially improve the outcome of radiotherapy. The expression of CD121a was not significantly among treatments indicating that 4-MU has no effect on the IL-1 receptor but suppresses only release of IL-1 $\beta$. However, we found that expression of CD126 and CD130 on cell surface was suppressed in the presence of 4-MU, suggesting that the exchange of inflammatory response between adjacent cells causing radioresistance was indirectly suppressed through inhibition of IL-1 $\beta$ and IL-6 release, and the receptors of IL-6.

HA is synthesized by HAS and is cleaved by hyaluronidase or oxidative stress, yielding a lower molecular weight form (36) that activates macrophages and stimulates the production of proinflammatory cytokines such as IL-1 $\beta$ through the HA/CD44 interaction thereby enhancing proliferation and angiogenesis (37). IL-1 $\beta$ and TNF $\alpha$ induced the human manganese superoxide dismutase gene such as SOD2, which is an enzyme that degrades active oxygen generated in cells (38). X-ray irradiation has been shown to produce reactive oxygen species (ROS) or free radicals that indirectly and/or directly induce DNA strand breakage and exert cytotoxic effects $(39,40)$. Radiosensitizing effect of $4-M U$ was suggested to be due to the accumulation of ROS.

In conclusion, 4-MU increased the sensitivity of HT1080 cells to X-ray radiation by inhibiting the production of the proinflammatory cytokines IL-1 $\beta$ and -6 . Thus, the efficacy of radiotherapy can be enhanced by co-administration of 4-MU. Additional research is needed to determine whether 4-MU can also prevent distant metastasis of cancer cells; however, our results highlight the clinical potential of 4-MU as a radiosensitizing agent that can improve treatment outcome.

\section{Acknowledgements}

Not applicable.

\section{Funding}

The present study was supported by KAKENHI, Young Scientists (B) (grant no. 17K16413).

\section{Availability of data and materials}

The datasets used and/or analyzed during the present study are available from the corresponding author on reasonable request.

\section{Authors' contributions}

RS, TN, KO, ET and YH conceived the study, participated in its design and coordination. RS and $\mathrm{KH}$ drafted the manuscript. RS, KH, KM and MC performed the experiments, and analyzed and interpreted the data. TN, KO, ET and YH critically revised the manuscript for important intellectual content. All authors read and approved the final manuscript.

\section{Ethics approval and consent to participate}

Not applicable.

\section{Patient consent for publication}

Not applicable.

\section{Competing interests}

The authors declare that they have no competing interests.

\section{References}

1. Lee SY, Jeong EK, Ju MK, Jeon HM, Kim MY, Kim CH, Park HG, Han SI and Kang HS: Induction of metastasis, cancer stem cell phenotype, and oncogenic metabolism in cancer cells by ionizing radiation. Mol Cancer 16: 10, 2017.

2. Hara T, Iwadate M, Tachibana K, Waguri S, Takenoshita S and Hamada N: Metastasis of breast cancer cells to the bone, lung, and lymph nodes promotes resistance to ionizing radiation. Strahlenther Onkol 193: 848-855, 2017.

3. Kuwahara Y, Mori M, Kitahara S, Fukumoto M, Ezaki T, Mori S, Echigo S, Ohkubo Y and Fukumoto M: Targeting of tumor endothelial cells combining $2 \mathrm{~Gy} /$ day of $\mathrm{X}$-ray with Everolimus is the effective modality for overcoming clinically relevant radioresistant tumors. Cancer Med 3: 310-321, 2014.

4. Kim JS, Chang JW, Yun HS, Yang KM, Hong EH, Kim DH, Um HD, Lee KH, Lee SJ and Hwang SG: Chloride intracellular channel 1 identified using proteomic analysis plays an important role in the radiosensitivity of HEp-2 cells via reactive oxygen species production. Proteomics 10: 2589-2604, 2010.

5. Hazawa M, Hosokawa Y, Monzen S, Yoshino H and Kashiwakura I: Regulation of DNA damage response and cell cycle in radiation-resistant HL60 myeloid leukemia cells. Oncol Rep 28: 55-61, 2012.

6. Arechaga-Ocampo E, Lopez-Camarillo C, Villegas-Sepulveda N, Gonzalez-De la Rosa CH, Perez-Añorve IX, Roldan-Perez R, Flores-Perez A, Peña-Curiel O, Angeles-Zaragoza O, Rangel Corona R, et al: Tumor suppressor miR-29c regulates radioresistance in lung cancer cells. Tumor Biol 39: 1010428317695010, 2017.

7. Zhou SB, Guo XW, Gu L and Ji SJ: Influential factors on radiotherapy efficacy and prognosis in patients with secondary lymph node metastasis after esophagectomy of thoracic esophageal squamous cell carcinoma. Cancer Manag Res 10: 217-225, 2018.

8. Yang J, Xu H, Guo X, Zhang J, Ye X, Yang Y and Ma X: Pretreatment inflammatory indexes as prognostic predictors for survival in colorectal cancer patients receiving neoadjuvant chemoradiotherapy. Sci Rep 8: 3044, 2018.

9. Matsuda T, Sumi Y, Yamashita K, Hasegawa H, Yamamoto M, Matsuda Y, Kanaji S, Oshikiri T, Nakamura T, Suzuki S and Kakeji Y: Outcomes and prognostic factors of selective lateral pelvic lymph node dissection with preoperative chemoradiotherapy for locally advanced rectal cancer. Int J Colorectal Dis 33: $367-374,2018$.

10. Xia Y,Li YH, Chen Y, Liu Q, Zhang JH, Deng JY, Ai TS, Zhu HT, Badakhshi $\mathrm{H}$ and Zhao KL: A phase II trial of concurrent chemoradiotherapy with weekly paclitaxel and carboplatin in advanced oesophageal carcinoma. Int J Clin Oncol 23: 458-465, 2018.

11. Fangzheng W, Chuner J, Quanquan S, Zhimin Y, Tongxin L, Jiping L, Sakamoto M, Peng W, Kaiyuan S, Weifeng Q, et al: Addition of 5-fluorouracil to docetaxel/cisplatin does not improve survival in locoregionally advanced nasopharyngeal carcinoma. Oncotarget 8: 115469-115479, 2017. 
12. Kim HJ, Choi GS, Park JS, Park SY, Cho SH, Lee SJ, Kang BW and Kim JG: Optimal treatment strategies for clinically suspicious lateral pelvic lymph node metastasis in rectal cancer. Oncotarget 8: 100724-100733, 2017.

13. Nakamura T, Takagaki K, Shibata S, Tanaka K, Higuchi T and Endo M: Hyaluronic-acid-deficient extracellular matrix induced by addition of 4-methylumbelliferone to the medium of cultured human skin fibroblasts. Biochem Biophys Res Commun 208: 470-475, 1995.

14. Kuroda Y, Kasai K, Nanashima N, Nozaka H, Nakano M, Chiba M, Yoneda $\mathrm{M}$ and Nakamura T: 4-Methylumbelliferone inhibits the phosphorylation of hyaluronan synthase 2 induced by 12-O-tetradecanoyl-phorbol-13-acetate. Biomed Res 34: 97-103, 2013.

15. Yates TJ, Lopez LE, Lokeshwar SD, Ortiz N, Kallifatidis G, Jordan A, Hoye K, Altman N and Lokeshwar VB: Dietary supplement 4-methylumbelliferone: An effective chemopreventive and therapeutic agent for prostate cancer. J Natl Cancer Inst 107: pii: djv085, 2015.

16. Piccioni F, Fiore E, Bayo J, Atorrasagasti C, Peixoto E, Rizzo M, Malvicini M, Tirado-González I, García MG, Alaniz L and Mazzolini G: 4-methylumbelliferone inhibits hepatocellular carcinoma growth by decreasing IL- 6 production and angiogenesis. Glycobiology 25: 825-835, 2015.

17. Li F, Hao P, Liu G, Wang W, Han R, Jiang Z and Li X: Effects of 4-methylumbelliferone and high molecular weight hyaluronic acid on the inflammation of corneal stromal cells induced by LPS. Graefes Arch Clin Exp Ophthalmol 255: 559-566, 2017.

18. Piao L, Canguo Z, Wenjie L, Xiaoli C, Wenli S and Li L: Lipopolysaccharides-stimulated macrophage products enhance Withaferin A-induced apoptosis via activation of caspases and inhibition of NF- $\mathrm{NB}$ pathway in human cancer cells. Mol Immunol 81: 92-101, 2017.

19. Yu H, Aravindan N, Xu J and Natarajan M: Inter- and intra-cellular mechanism of NF-kB-dependent survival advantage and clonal expansion of radio-resistant cancer cells. Cell Signal 31: 105-111, 2017.

20. Mochizuki D, Adams A, Warner KA, Zhang Z, Pearson AT, Misawa K, McLean SA, Wolf GT and Nör JE: Anti-tumor effect of inhibition of IL-6 signaling in mucoepidermoid carcinoma. Oncotarget 6: 22822-22835, 2015 .

21. Lee SO, Yang X, Duan S, Tsai Y, Strojny LR, Keng P and Chen Y: IL-6 promotes growth and epithelial-mesenchymal transition of CD133+ cells of non-small cell lung cancer. Oncotarget 7: 6626-6638, 2016.

22. Saga R, Monzen S, Chiba M, Yoshino H, Nakamura T and Hosokawa Y: Anti-tumor and anti-invasion effects of a combination of 4-methylumbelliferone and ionizing radiation in human fibrosarcoma cells. Oncol Lett 13: 410-416, 2017.

23. Livak KJ and Schmittgen TD: Analysis of relative gene expression data using real-time quantitative PCR and the 2(-Delta Delta C(T)) method. Methods 25: 402-408, 2001

24. Lokeshwar VB, Lopez LE, Munoz D, Chi A, Shirodkar SP, Lokeshwar SD, Escudero DO, Dhir N and Altman N: Antitumor activity of hyaluronic acid synthesis inhibitor 4-methylumbelliferone in prostate cancer cells. Cancer Res 70: 2613-2623, 2010.

25. Arai E,Nishida Y, Wasa J,Urakawa H,Zhuo L, Kimata K, Kozawa E, Futamura $\mathrm{N}$ and Ishiguro $\mathrm{N}$ : Inhibition of hyaluronan retention by 4-methylumbelliferone suppresses osteosarcoma cells in vitro and lung metastasis in vivo. Br J Cancer 105: 1839-1849, 2011.
26. Urakawa H, Nishida Y, Wasa J, Arai E, Zhuo L, Kimata K, Kozawa E, Futamura $\mathrm{N}$ and Ishiguro $\mathrm{N}$ : Inhibition of hyaluronan synthesis in breast cancer cells by 4 -methylumbelliferone suppresses tumorigenicity in vitro and metastatic lesions of bone in vivo. Int J Cancer 130: 454-466, 2012.

27. Li Y, Li L, Brown TJ and Heldin P: Silencing of hyaluronan synthase 2 suppresses the malignant phenotype of invasion breast cancer cells. Int J Cancer 120: 2557-2567, 2007.

28. Nazarenko I, Marhaba R, Reich E, Voronov E, Vitacolonna M, Hildebrand D, Elter E, Rajasagi M, Apte RN and Zöller M: Tumorigenicity of IL-1alpha- and IL-1beta-deficient fibrosarcoma cells. Neoplasia 10: 549-562, 2008.

29. Sun Y and Ma L: The emerging molecular machinery and therapeutic targets of metastasis. Trends Pharmacol Sci 36: 349-359, 2015.

30. Tamari $\mathrm{Y}, \mathrm{Kashino} \mathrm{G}$ and Mori $\mathrm{H}$ : Acquisition of radioresistance by IL- 6 treatment is caused by suppression of oxidative stress derived from mitochondria after $\gamma$-irradiation. J Radiat Res 58: 412-420, 2017.

31. Chen Y, Zhang F, Tsai Y, Yang X, Yang L, Duan S, Wang X, Keng $\mathrm{P}$ and Lee SO: IL-6 signaling promotes DNA repair and prevents apoptosis in CD133+ stem-like cells of lung cancer after radiation. Radiat Oncol 10: 227, 2015.

32. Duan S, Tsai Y, Keng P, Chen Y, Lee SO and Chen Y: IL-6 signaling contributes to cisplatin resistance in non-small cell lung cancer via the up-regulation of anti-apoptotic and DNA repair associated molecules. Oncotarget 6: 27651-27660, 2015.

33. Stanam A, Gibson-Corley KN, Love-Homan L, Ihejirika N and Simons AL: Interleukin-1 blockade overcomes erlotinib resistance in head and neck squamous cell carcinoma. Oncotarget 7: 76087-76100, 2016.

34. Grivennikov SI and Karin M: Dangerous liaisons: STAT3 and NF-kappaB collaboration and crosstalk in cancer. Cytokine Growth Factor Rev 21: 11-19, 2010.

35. Hei TK, Zhou H, Chai Y, Ponnaiya B and Ivanov VN: Radiation induced non-targeted response: Mechanism and potential clinical implications. Curr Mol Pharmacol 4: 96-105, 2011.

36. Nagy N, Kuipers HF, Frymoyer AR, Ishak HD, Bollyky JB, Wight TN and Bollyky PL: 4-methylumbelliferone treatment and hyaluronan inhibition as a therapeutic strategy in inflammation, autoimmunity, and cancer. Front Immunol 6: 123, 2015

37. Hauser-Kawaguchi A, Luyt LG and Turley E: Design of peptide mimetics to block pro-inflammatory functions of HA fragments. Matrix Biol pii: S0945-053X: 30444-30454, 2018.

38. Xu Y, Kiningham KK, Devalaraja MN, Yeh CC, Majima H, Kasarskis EJ and St Clair DK: An intronic NF-kappaB element is essential for induction of the human manganese superoxide dismutase gene by tumor necrosis factor-alpha and interleukin-1beta. DNA Cell Biol 18: 709-722, 1999.

39. Bajinskis A, Natarajan AT, Erixon K and Harms-Ringdahl M: DNA double strand breaks induced by the indirect effect of radiation are more efficiently repaired by non-homologous end joining compared to homologous recombination repair. Mutat Res 756: 21-29, 2013

40. Vignard J, Mirey G and Salles B: Ionizing-radiation induced DNA double-strand breaks: A direct and indirect lighting up. Radiother Oncol 108: 362-369, 2013. 